\title{
Effects of Different Inoculation Regimes of Torulaspora delbrueckii and Oenococcus oeni on Fermentation Kinetics and Chemical Constituents of Durian Wine
}

\author{
Y. Lu ${ }^{1}$, J.-Y. Chua ${ }^{1}$, M.K.W. Voon ${ }^{1}$, D. Huang ${ }^{1,2}$, P.-R. Lee ${ }^{3}$, S.-Q. Liu ${ }^{1,2 *}$
}

(1) Food Science and Technology Programme, Department of Chemistry, National University of Singapore, Science Drive 3, Singapore 117543, Singapore

(2) National University of Singapore (Suzhou) Research Institute, 377 Lin Quan Street, Suzhou Industrial Park, Jiangsu 215123, China

(3) Shiro Corporation Pte Ltd, 1 Senoko Avenue, Singapore 758297, Singapore

Submitted for publication: May 2017

Accepted for publication: July 2017

Keywords: Durian wine, Torulaspora delbrueckii, Oenococcus oeni, malolactic fermentation, inoculation time

\begin{abstract}
This work evaluated the effects of inoculation time of Oenococcus oeni on the kinetics of fermentation and chemical constituents of durian wine produced using a non-Saccharomyces yeast, Torulaspora delbrueckii. The growth of $T$. delbrueckii in mixed-culture fermentations was significantly adversely affected by the presence of $O$. oeni, and the growth of malolactic bacteria was also affected by the metabolism of yeast during fermentation. The level of ethanol produced in simultaneous alcoholic and malolactic fermentation (SIM, 6.93\%, v/v) was comparable to that in the Saccharomyces cerevisiae EC-1118 control (6.75\%, v/v); both levels were relatively higher than that in the $T$. delbrueckii Biodiva control $(6.39 \%, \mathrm{v} / \mathrm{v})$ and the other two sequential fermentations (oenococci inoculated after four and seven days of alcoholic fermentation, SEQ $4^{\text {th }}, 6.34 \%$ and SEQ $7^{\text {th }}, 6.33 \% \mathrm{v} / \mathrm{v}$ respectively). The final concentrations of organic acids and esters in the mixed-culture wines were correlated with the inoculation time of $O$. oeni. SIM produced relatively higher levels of ethyl esters (ethyl esters of hexanoate, octanoate, decanoate and lactate) and acetate esters (ethyl acetate and isoamyl acetate) than those in SEQ $4^{\text {th }}$, SEQ $7^{\text {th }}$ and the Biodiva control. This suggests that SIM would contribute fruity aroma properties to and modulate the mouthfeel of durian wine. The production of 3-(ethylthio)-1-propanol could compensate for the weak onion-like odour caused by the decrease in initial volatile sulphur compounds. Overall, this research suggests that SIM treatment is an effective way to produce durian wine with higher ester production.
\end{abstract}

\section{INTRODUCTION}

In recent years, an increasing number of researchers have been paying more attentions to wines from tropical fruit such as banana (Byarugaba-Bazirake et al., 2013), papaya (Lee et al., 2010) and lychee (Chen \& Liu, 2016) due to their pleasant and characteristic flavours. Other tropical fruits, such as durian and mangosteen, are also promising for novel fruit wine production but have received much less research attention than other fruits. Durian (Durio zibethinus Murr.) is a unique and popular tropical fruit grown widely in Southeast Asia. Durian is not only a good source of carbohydrate, fat, fibre and protein, but also contains abundant phenolic compounds, and medium-chain saturated and unsaturated fatty acids (Haruenkit et al., 2010). In addition, there are more than 170 volatile aroma compounds found in the durian flavour compound array, including esters (e.g. ethyl 2-methylbutyrate) and volatile sulphur compounds (e.g. thiols and sulphides) (Ho \& Bhat, 2015). Durian is normally consumed fresh and its availability is limited to its fruiting season from May to August, and short shelf life of two to five days at room temperature (Haruenkit et al., 2010). Therefore, alcoholic fermentation (AF) of durian pulp may provide an alternative way to preserve, extend shelf life and add value to this fruit.

Alcoholic fermentation is normally conducted by Saccharomyces cerevisiae strains with the conversion of sugars to ethanol, and yeasts play a significant role in the production and modulation of the wine aroma profile by releasing flavour compounds from fruit precursors or synthesising yeast-derived aroma compounds (Viana et al., 2008; Sun et al., 2013; Tristezza et al., 2013, 2016). Recently, non-Saccharomyces yeasts like Torulaspora delbrueckii received more attention due to their potential positive roles in the organoleptic characteristics of wines, such as the production of low levels of volatile acidity and acetaldehyde,

*Corresponding author: E-mail address: chmlsq@nus.edu.sg [Tel.: +65 6516 2687; Fax: +65 67757895$]$ 
which are beneficial in terms of wine quality (Bely et al., 2008). Previous studies have reported that T. delbrueckii possessed good fermentation efficiencies with residual sugar levels of less than $2 \mathrm{~g} / \mathrm{L}$ and produced comparable levels of ethanol to S. cerevisiae when fermented at $20^{\circ} \mathrm{C}$ ( $\mathrm{Lu}$ et al., 2015, 2016a). Further, T. delbrueckii showed a better capacity for producing higher alcohols and ethyl esters, which could contribute to the fruity notes and aroma complexity of the wines (Lu et al., 2016a).

Malolactic fermentation (MLF) is an enzyme-mediated process in which L-malic acid is decarboxylated into L-lactic acid and carbon dioxide by lactic acid bacteria (LAB), mainly by Oenococcus oeni (Nehme et al., 2010; Knoll et al., 2011). Malolactic fermentation is usually conducted after $\mathrm{AF}$ and could improve wine quality via deacidification, the production of desirable aroma compounds and the enhancement of microbial stability (Izquierdo et al., 2012). O. oeni strains (Viniflora, Enoferm Beta and PN4) are employed in MLF due to their better tolerance of the harsh physicochemical conditions, such as low $\mathrm{pH}$, high ethanol content, presence of inhibitory metabolites (e.g. $\mathrm{SO}_{2}$ and medium-chain fatty acids) and low nutritional status (Alexandre et al., 2004; Nehme et al., 2010).

Various studies have shown that simultaneous AF and MLF (SIM) using $S$. cerevisiae and $O$. oeni can be carried out successfully, especially in grape and lychee wines (Abrahamse \& Bartowsky, 2012; Izquierdo et al., 2012; Garofalo et al., 2015; Chen \& Liu, 2016). Chen \& Liu (2016) reported that simultaneous AF by $S$. cerevisiae MERIT. ferm and MLF by $O$. oeni Viniflora could improve the production of aroma compounds in lychee wine. However, Sun et al. (2013) reported that sequential inoculation (SEQ) of $S$. cerevisiae and $O$. oeni has great potential for the production of cherry wines. Therefore, it seems that the different inoculation strategies, namely SIM and SEQ, may have different effects on wine aroma composition (Mendoza et al., 2011). This is because the success or failure of MLF is closely associated with yeast and bacterial strain pairing, and the possible interactions between them (Alexandre et al., 2004; Nehme et al., 2010). In addition, little information is available on the mixed culture fermentation initiated by nonSaccharomyces yeasts and oenococci.

Our previous study assessed and compared the compatibility of three commercial strains of O. oeni (Viniflora, PN4 and Enoferm Beta) with T. delbrueckii Biodiva via simultaneous AF and MLF in durian wine fermentation and showed that $O$. oeni PN4 had better compatibility than the other two O. oeni strains (Lu et al., 2017). The present study was a further investigation, and the objective was to examine, for the first time, the kinetics of yeast and bacterial population, organic acids and aroma compounds related to the different inoculation regimes of $T$. delbrueckii Biodiva and $O$. oeni PN4 during durian wine fermentation.

\section{MATERIALS AND METHODS}

\section{Microbial strains and growth media}

Saccharomyces cerevisiae var. bayanus EC-1118, Torulaspora delbrueckii Biodiva and Oenococcus oeni PN4 were purchased from Lallemand Inc. (Brooklyn Park, Australia). A sterile broth was prepared by autoclaving $\left(121^{\circ} \mathrm{C}, 15 \mathrm{~min}\right)$, which consisted of $2.5 \mathrm{~g}$ of yeast extract, $2.5 \mathrm{~g}$ of bacteriological peptone, $2.5 \mathrm{~g}$ of malt extract and $20 \mathrm{~g}$ of glucose per litre of water. The freeze-dried yeast strains were propagated in the sterile broth $(\mathrm{pH} \mathrm{5.0)}$ for $72 \mathrm{~h}$ at $20^{\circ} \mathrm{C}$ and stored at $-80^{\circ} \mathrm{C}$ before use. The broth cultures $(5 \%, \mathrm{~V} / \mathrm{v})$ were propagated in pasteurised durian pulp $\left(60^{\circ} \mathrm{C}, 20 \mathrm{~min}\right)$ and incubated statically at $30^{\circ} \mathrm{C}$ for $72 \mathrm{~h}$ in order to achieve colony-forming units (CFU) of at least $1 \times 10^{7}$ per $\mathrm{mL}$, which served as the pre-cultures for final inoculation. The freeze-dried $O$. oen $i$ was propagated in a modified MRS (supplemented with $20 \%$ apple juice, v/v) broth (Sigma-Aldrich, Singapore) for five days at $30^{\circ} \mathrm{C}$ to obtain pure cultures with cell populations of at least $1 \times 10^{7}$ $\mathrm{CFU} / \mathrm{mL}$, and stored at $-80^{\circ} \mathrm{C}$ until use. The bacteria preculture was prepared by inoculating $5 \%(\mathrm{v} / \mathrm{v})$ broth culture (O. oeni PN4) into the modified MRS broth (the same as above) for five days at $30^{\circ} \mathrm{C}$ to obtain cell populations of over $1 \times 10^{7} \mathrm{CFU} / \mathrm{mL}$.

\section{Durian pulp preparation and fermentation}

The pulp was prepared in our laboratory from durian fruits (D666 cultivar) that were imported from Malaysia; it was homogenised and diluted with deionised water at a 3:7 (w/w) ratio to form a puree. The $\mathrm{pH}$ of the puree $(\mathrm{pH}$ 6.85) was adjusted to $\mathrm{pH} 4.0$ using $1 \mathrm{~mol} / \mathrm{L}$ of DL-malic acid, and the soluble solids content $\left(8.25^{\circ} \mathrm{Brix}\right)$ was adjusted to $20^{\circ} \mathrm{Brix}$ with sucrose. The adjusted pulp was then pasteurised at $60^{\circ} \mathrm{C}$ for $20 \mathrm{~min}$. Following that, spread plating was performed to verify the efficiency of pasteurisation. Triplicate laboratory fermentations were conducted using pasteurised durian pulp (300 mL each) in $500 \mathrm{~mL}$ sterile Erlenmeyer flasks. SIM was conducted by simultaneously inoculating $T$. delbrueckii Biodiva $\left(6.02 \times 10^{5} \mathrm{CFU} / \mathrm{mL}\right)$ and $O$. oeni PN4 $(6.61 \times$ $10^{5} \mathrm{CFU} / \mathrm{mL}$ ). The same amount of yeast and bacteria was inoculated in the SEQ treatments (SEQ $4^{\text {th }}$ and SEQ $7^{\text {th }}$ days). SEQ $4^{\text {th }}$ and SEQ $7^{\text {th }}$ were conducted by inoculating oenococci after four and seven days of AF by T. delbrueckii Biodiva. In addition, the same amount of $T$. delbrueckii Biodiva monoculture was inoculated as the Biodiva control. The commercial S. cerevisiae EC-1118 $\left(8.91 \times 10^{5} \mathrm{CFU} / \mathrm{mL}\right)$ was also inoculated as the EC-1118 control. The inoculated pulp was allowed to ferment statically at $30^{\circ} \mathrm{C}$ for 14 days, based on previous studies (Lu et al., 2016b, 2017). Samples were taken periodically at days $0,2,4,5,7,8,10$ and 14 to assess the yeast and bacteria growth, ${ }^{\circ}$ Brix, $\mathrm{pH}$, sugars, organic acids and volatile compounds. All samples were stored at $-20^{\circ} \mathrm{C}$ before analysis.

\section{Analytical determinations}

Yeast growth was monitored by spread-plating onto potato dextrose agar (PDA), and the plates were incubated at $30^{\circ} \mathrm{C}$ for two days ( $\mathrm{Lu}$ et al., 2017). O. oeni was monitored on modified MRS agar and incubated at $30^{\circ} \mathrm{C}$ for five days under anaerobic conditions. The MRS agar plates were prepared by dissolving MRS powder (49.6 g) in deionised water $\left(800 \mathrm{~mL}\right.$ ) with $\operatorname{Natamax}^{\circledR}$ (a natural antimicrobial with natamycin as its active ingredient, $0.1 \mathrm{~g}$, Danisco Singapore Pte Ltd, Singapore), followed by autoclaving at $121^{\circ} \mathrm{C}$ for $15 \mathrm{~min}$, after which sterile apple juice $(200 \mathrm{~mL}$, $\mathrm{pH}$ 5.5) was added before dispensing. Natamax ${ }^{\circledR}$ was used 
to inhibit the growth of yeasts. ${ }^{\circ}$ Brix and $\mathrm{pH}$ were measured using a refractometer (ATAGO, Tokyo, Japan) and $\mathrm{pH}$ meter (Metrohm, Herisau, Switzerland) respectively.

Samples for sugar (glucose, fructose and sucrose) and organic acid determination were centrifuged twice $\left(\times 10000 \mathrm{~g}, 4^{\circ} \mathrm{C}\right)$ for $10 \mathrm{~min}$ and filtered through $0.20 \mu \mathrm{m}$ filters (Sartorius, Gottingen, Germany). Analysis was conducted using high-performance liquid chromatography (HPLC, Shimadzu, Kyoto, Japan) coupled with LC-10AT system. Sugars were determined using an evaporative light-scattering detector (ELSD) connected to a Zorbax carbohydrate column (150 mm $\times 4.6 \mathrm{~mm}$; Agilent, Santa Clara, CA, USA), eluting at $30^{\circ} \mathrm{C}$ with a mobile phase of acetonitrile/water (80:20, $\mathrm{v} / \mathrm{v}$ ) at a flow rate of $1.4 \mathrm{~mL} / \mathrm{min}$. As for organic acids, a photodiode array detector set at $210 \mathrm{~nm}$ was connected to a Supelcogel C-610H column $(300 \mathrm{~mm} \times 7.8 \mathrm{~mm}$; Supelco/ Sigma-Aldrich, Barcelona, Spain). The mobile phase was set to flow at $0.4 \mathrm{~mL} / \mathrm{min}$ and the column was eluted at $40^{\circ} \mathrm{C}$ with $0.1 \%(\mathrm{v} / \mathrm{v})$ sulphuric acid. The identification of the compounds was based on the comparison of retention times of the samples against those of pure standards (SigmaAldrich, St Louis, MO, USA) run under the same conditions. The concentration was calculated based on standard curves $\left(R^{2}>0.99\right)$.

Volatile compounds were performed using a gas chromatograph (GC)/mass spectrometer (MS) with a flame ionisation detector (FID) using headspace (HS) solid-phase microextraction (SPME) with a carboxen-poly (dimethylsiloxane) fibre (85 $\mu \mathrm{m}$ coating; Supelco/SigmaAldrich, Barcelona, Spain). Before analysis, an aliquot of durian wine was adjusted to $\mathrm{pH} 2.5 \mathrm{using} 1 \mathrm{~mol} / \mathrm{L} \mathrm{HCl}$. The aliquot of the durian wine $(5 \mathrm{~mL})$ was extracted at $60^{\circ} \mathrm{C}$ for $50 \mathrm{~min}$ by a HS-SPME fibre at a rotational speed of $250 \mathrm{rpm}$. The SPME fibre was then desorbed at $250^{\circ} \mathrm{C}$ for $3 \mathrm{~min}$ at the injection port of an Agilent 7890A GC coupled to an Agilent 5975C triple-axis MS and FID. With helium at $1.2 \mathrm{~mL} / \mathrm{min}$, The separation of the volatile compounds occurred in the Agilent DB-FFAP capillary column $(60 \mathrm{~m} \times 0.25 \mathrm{~mm}$ i.d), coated with a $0.25 \mathrm{~mm}$ thick film of polyethylene glycol modified with nitroterephthalic acid. The temperature of the $\mathrm{GC}$ was programmed to increase from $50^{\circ} \mathrm{C}$ to $230^{\circ} \mathrm{C}$ at a rate of $5^{\circ} \mathrm{C} / \mathrm{min}$ within $30 \mathrm{~min}$. The eluate was passed through the FID and MS, where ionisation was produced with $70 \mathrm{eV}$ electron impact at $230^{\circ} \mathrm{C}$. The identification of volatiles was carried out by matching the mass spectra with those in the Wiley MS library, and was confirmed with the linear retention index (LRI) values. External standards (Firmenich Asia Ltd, Singapore) were used to quantify the selected volatiles that were considered as significant for durian wine flavour according to the literature. The $R^{2}$ values of the standard curves were at least 0.98 . The contribution of a volatile compound to overall fruit wine flavour was evaluated by its odour activity value (OAV) (Guth, 1997).

\section{Statistical analysis}

All samples were analysed in triplicate and the data were expressed as the mean \pm standard deviation. A one-way analysis of variance (ANOVA) and Tukey's test (SPSS Corporation, Chicago, IL, USA, version 17.0) were performed on the experimental data obtained to compare the statistical differences between the durian pulp and final wines. The difference was considered statistically significant if $p<0.05$. Principal component analysis (PCA) was carried out on selected volatile compounds using MATLAB R2008a (Mathworks, Massachusetts, USA).

\section{RESULTS AND DISCUSSION}

\section{Evolution of microbial populations and fermentation kinetics}

The evolution of yeasts and malolactic bacteria populations, and the kinetic changes in ${ }^{\circ}$ Brix and $\mathrm{pH}$, are shown in Fig. 1. Viable yeast populations (Fig. 1a) in all fermentations reached their maximum, ranging from $8.3 \times 10^{7} \mathrm{CFU} / \mathrm{mL}$ (S. cerevisiae EC-1118) to $2.2 \times 10^{8} \mathrm{CFU} / \mathrm{mL}$ (SIM), on day 2 , and then followed a significantly different pattern of evolution, except for the Biodiva control and SEQ $7^{\text {th }}$ (which followed the same trend). T. delbrueckii Biodiva in SIM, SEQ $4^{\text {th }}$ and SEQ $7^{\text {th }}$ was undetectable on day 7 , day 10 and day 14 respectively (Fig. 1a). T. delbrueckii Biodiva in the control was undetectable by day 14 , while $S$. cerevisiae EC-1118 in the control declined to around $1.0 \times 10^{5} \mathrm{CFU} / \mathrm{mL}$ at the end of the fermentation (Fig. 1a). The growth of T. delbrueckii in mixed-culture fermentations (SIM and both SEQ), especially in SIM and SEQ $4^{\text {th }}$, was significantly adversely affected by the presence of $O$. oeni $\mathrm{PN} 4$. This is consistent with a previous study, which showed that the growth of $S$. cerevisiae MERIT could be interfered with by $O$. oeni Viniflora in simultaneous $\mathrm{AF}$ and MLF in lychee wine (Chen \& Liu, 2016). In contrast, a previous study showed that the presence of $O$. oeni $\mathrm{C} 22 \mathrm{~L} 9$ did not influence the growth of $S$. cerevisiae VRB and VN (Izquierdo et al., 2012), or that $S$. cerevisiae EC-1118 could adapt to the presence of $O$. oeni Viniflora (Taniasuri et al., 2016). It is important to note that the interaction between yeast and $O$. oen $i$ can vary with strains; the outcome may differ even with the same strain but different matrices.

The possible reasons for the different fermentation performance could be the different yeasts (nonSaccharomyces used in the present study) or bacteria used in the different fermentations. The role played by the yeasts and bacterial strains and the fermentation condition would affect their compatibility in wine fermentation (Taniasuri et al., 2016). In addition, malolactic bacteria may deplete certain nutrients or survival factors required by yeasts (Alexandre et al., 2004). Furthermore, the higher levels of acetic acid produced in SIM and SEQ (Table 1; Fig. 2) might be another reason for the early yeast cell death (Jussier et al., 2006; Taniasuri et al., 2016). Acetic acid (undissociated form) could pass through the yeast cell membrane via passive diffusion, leading to intracellular acidification by protonation and resulting in the reduction of cell biomass due to the ATP channelling $\mathrm{pH}$ homeostasis (Graves et al., 2007). Moreover, it is important to note that the production of lactic acid was inversely correlated with the kinetics of T. delbrueckii in SIM and SEQ (Fig. 2); therefore, lactic acid may have resulted in the decline in T. delbrueckii, just like acetic acid.

The cell populations of $O$. oeni PN4 in SIM increased gradually to $1.5 \times 10^{7} \mathrm{CFU} / \mathrm{mL}$ by day 2 and then decreased slightly to $5.8 \times 10^{6} \mathrm{CFU} / \mathrm{mL}$ by day 14 . In SEQ $4^{\text {th }}$ and SEQ $7^{\text {th }}$, on the other hand, the bacterial populations first decreased slightly (by day 5 and 8 respectively), and then 

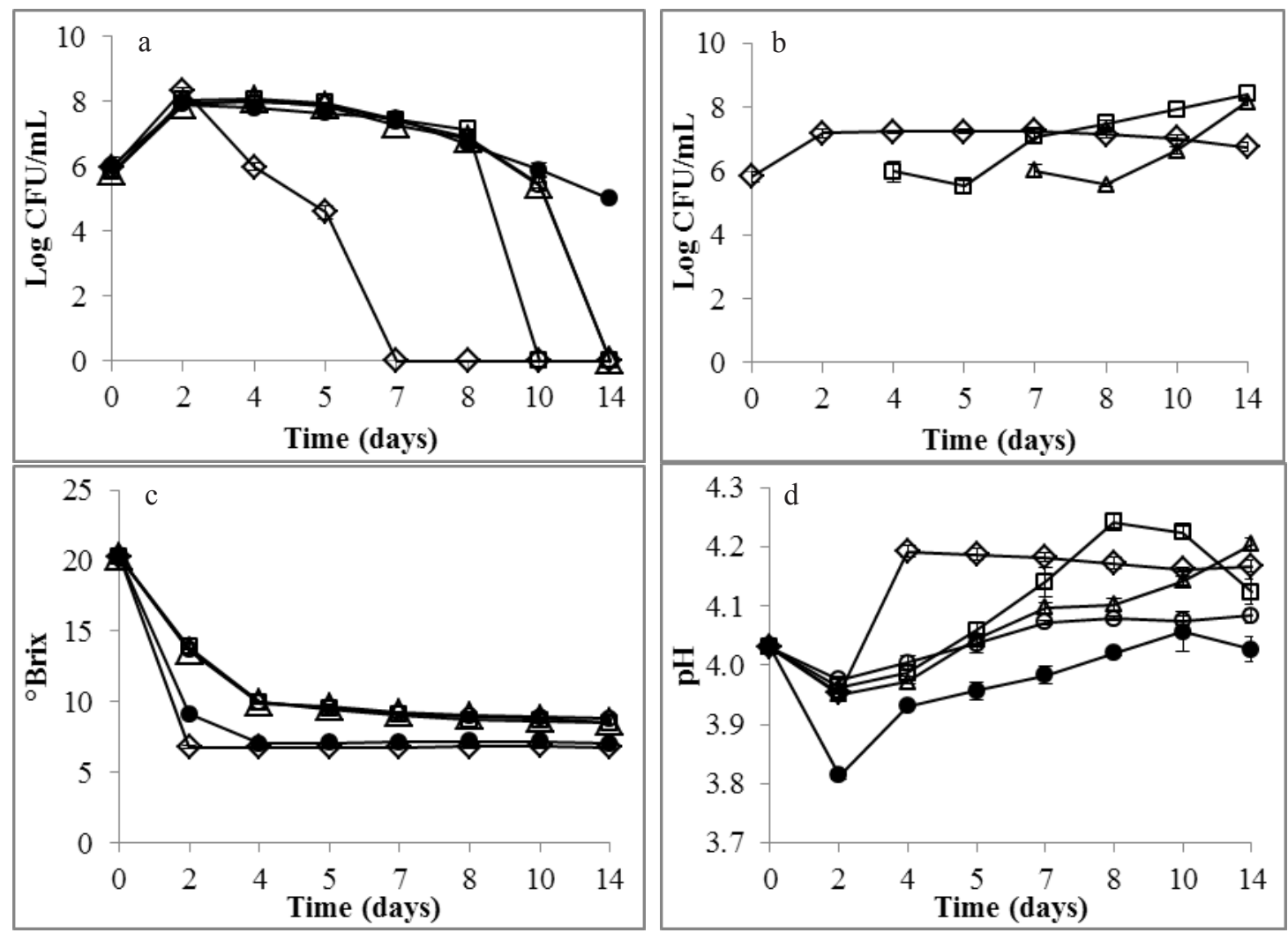

FIGURE 1

(a) Viable cell count of yeast; (b) viable cell count of $O$. oeni PN4 during durian wine fermentation; (c) changes in ${ }^{\circ}$ Brix; (d) changes in $\mathrm{pH}$ during durian wine fermentation. (•) S. cerevisiae EC-1118 monoculture fermentation; ( $(\circ)$ T. delbrueckii Biodiva monoculture fermentation; $(\diamond)$ simultaneous inoculation (SIM) of T. delbrueckii Biodiva and O. oeni PN4; ( $\square$ ) sequential inoculation (SEQ $4^{\text {th }}$ ): O. oeni PN4 inoculated after four days of fermentation with $T$. delbrueckii Biodiva; $(\Delta)$ sequential inoculation (SEQ $7^{\text {th }}$ ): O. oeni PN4 inoculated after seven days of fermentation with T. delbrueckii Biodiva. The values are the means of triplicate fermentations \pm standard deviation.

increased to $2.6 \times 10^{8}$ and $1.5 \times 10^{8} \mathrm{CFU} / \mathrm{mL}$ respectively (Fig. 1b). Our results agree with those reported by Mendoza et al. (2011) and Lu et al. (2016b), who found that bacterial populations did not decrease significantly after simultaneous AF and MLF. Izquierdo et al. (2012) also observed that there was an early bacterial cell death in SEQ fermentations. This could be due to the duration of adaption by $O$. oeni to the environmental stresses (e.g. $\mathrm{pH}$ and ethanol content) within the first few days (Fig. 1b), after which their survival and performance improved as the fermentation progressed. At the end of the fermentation (day 14), the bacterial viability in SEQ $4^{\text {th }}$ and SEQ $7^{\text {th }}$ was similar, but significantly higher than that in SIM. This might be due to the fact that bacteria were stimulated in SEQ, or maybe they did not grow more in SIM because of lactic acid formation or because they had already consumed all the available nutrients (Alexandre et al., 2004).

All treatments showed similar trends in total soluble solids, with the ${ }^{\circ}$ Brix values rapidly decreasing within the first four days and remaining stable onwards (Fig. 1c). The ${ }^{\circ}$ Brix value in SIM decreased rapidly from $20.2 \%$ to around $6.8 \%$ by day 2 , while in the T. delbrueckii Biodiva control, SEQ $4^{\text {th }}$ and SEQ $7^{\text {th }}$ the ${ }^{\circ}$ Brix values decreased to around $8.6 \%$ by day 5 (Fig. 1c). It is important to highlight that the final ${ }^{\circ}$ Brix value in SIM was comparable to that in the $S$. cerevisiae EC-1118 control, but was significantly lower than that in the $T$. delbrueckii Biodiva control, SEQ $4^{\text {th }}$ and SEQ $7^{\text {th }}$ (Table 1, Fig. 1c). In SIM, sucrose, glucose and fructose were depleted in the first four days (data not shown), while in SEQ $4^{\text {th }}$ and SEQ $7^{\text {th }}$, the utilisation of sugars followed the same trend as the T. delbrueckii Biodiva control, with high amounts of residual fructose $(13 \mathrm{~g} / \mathrm{L})$ and glucose $(6 \mathrm{~g} / \mathrm{L})$ respectively (Table 1$)$. This may indicate that the bacteria in SIM could improve the utilisation of sugars during fermentation, corresponding to its lower levels of residual sugars (sum of fructose, glucose and sucrose, $<2 \mathrm{~g} / \mathrm{L}$ ). The residual sugars in the T. delbrueckii Biodiva control, SEQ $4^{\text {th }}$ and SEQ $7^{\text {th }}$ were around $18 \mathrm{~g} / \mathrm{L}$ at day 14 (Table 1), which was significantly higher than that in the S. cerevisiae EC-1118 control $(<1 \mathrm{~g} / \mathrm{L})$.

Our results are in line with the findings of Chen and Liu (2016), who reported that $O$. oeni did not affect the sugar utilisation of yeasts ( $S$. cerevisiae MERIT. ferm) in simultaneous AF and MLF in lychee wine fermentation. Jussier et al. (2006) reported that $O$. oeni could metabolise sugars, especially fructose and glucose, to produce ethanol, carbon dioxide and organic acids (e.g. lactic acid and acetic acid) in SIM. In addition, the level of ethanol produced in SIM $(6.93 \%, \mathrm{v} / \mathrm{v})$ was comparable to that in the $S$. cerevisiae EC-1118 control $(6.75 \%$, v/v), which was relatively higher 
TABLE 1

Oenological parameters of durian wines fermented simultaneously and sequentially with $T$. delbrueckii and $O$. oeni ${ }^{\#}$

\begin{tabular}{|c|c|c|c|c|c|c|}
\hline \multirow[b]{2}{*}{ Parameters } & \multirow[b]{2}{*}{ Durian puree } & \multicolumn{5}{|c|}{ Durian wines (day 14) } \\
\hline & & EC-1118 & Biodiva & SIM & SEQ $4^{\text {th }}$ & $\operatorname{SEQ} 7^{\text {th }}$ \\
\hline $\mathrm{pH}$ & $4.03 \pm 0.00 \mathrm{a}$ & $4.03 \pm 0.02 \mathrm{a}$ & $4.08 \pm 0.01 b$ & $4.17 \pm 0.01 \mathrm{c}$ & $4.12 \pm 0.02 d$ & $4.20 \pm 0.01 \mathrm{c}$ \\
\hline${ }^{\circ} \operatorname{Brix}(\%)$ & $20.23 \pm 0.18 \mathrm{a}$ & $7.04 \pm 0.15 b$ & $8.80 \pm 0.19 c$ & $6.75 \pm 0.06 b$ & $8.50 \pm 0.14 \mathrm{c}$ & $8.55 \pm 0.17 \mathrm{c}$ \\
\hline Ethanol (\%) & $0.08 \pm 0.01 \mathrm{a}$ & $6.75 \pm 0.47 b$ & $6.39 \pm 0.28 b$ & $6.93 \pm 0.40 b$ & $6.34 \pm 0.43 b$ & $6.33 \pm 0.36 b$ \\
\hline \multicolumn{7}{|l|}{ Sugars $(g / L)$} \\
\hline Fructose & $9.51 \pm 0.32 \mathrm{a}$ & $0.10 \pm 0.00 \mathrm{~b}$ & $13.02 \pm 0.81 \mathrm{c}$ & $0.16 \pm 0.02 b$ & $12.07 \pm 0.75 \mathrm{c}$ & $12.98 \pm 0.58 \mathrm{c}$ \\
\hline Glucose & $14.86 \pm 0.30 \mathrm{a}$ & $0.29 \pm 0.01 b$ & $5.59 \pm 0.36 c$ & $0.79 \pm 0.05 b$ & $6.20 \pm 0.50 c$ & $5.68 \pm 0.21 c$ \\
\hline Sucrose & $218.47 \pm 2.19 a$ & $0.21 \pm 0.01 b$ & $0.43 \pm 0.05 b$ & $0.48 \pm 0.02 b$ & $0.38 \pm 0.05 b$ & $0.44 \pm 0.04 b$ \\
\hline \multicolumn{7}{|l|}{ Organic acid (g/L) } \\
\hline Acetic acid & $0.725 \pm 0.011 \mathrm{a}$ & $1.173 \pm 0.021 b$ & $1.033 \pm 0.026 \mathrm{c}$ & $1.275 \pm 0.005 \mathrm{~d}$ & $1.966 \pm 0.004 \mathrm{e}$ & $1.727 \pm 0.062 f$ \\
\hline$\alpha$-Ketoglutaric acid & $0.078 \pm 0.004 a$ & $0.140 \pm 0.006 b$ & $0.135 \pm 0.007 b$ & $0.100 \pm 0.015 \mathrm{ab}$ & $0.075 \pm 0.007 \mathrm{a}$ & $0.100 \pm 0.004 \mathrm{ab}$ \\
\hline Citric acid & $0.485 \pm 0.017 \mathrm{a}$ & $0.204 \pm 0.006 b$ & $0.158 \pm 0.009 \mathrm{c}$ & $0.101 \pm 0.005 \mathrm{~d}$ & nd & nd \\
\hline Lactic acid & $0.228 \pm 0.016 \mathrm{a}$ & $1.124 \pm 0.012 b$ & $0.591 \pm 0.019 \mathrm{c}$ & $3.667 \pm 0.040 \mathrm{~d}$ & $3.933 \pm 0.229 d$ & $3.357 \pm 0.067 \mathrm{e}$ \\
\hline Malic acid & $6.356 \pm 0.072 \mathrm{a}$ & $3.817 \pm 0.026 b$ & $5.670 \pm 0.074 c$ & $2.529 \pm 0.389 d$ & $3.582 \pm 0.049 b$ & $3.830 \pm 0.012 b$ \\
\hline Oxalic acid & $0.008 \pm 0.000 \mathrm{a}$ & $0.009 \pm 0.001 \mathrm{a}$ & $0.008 \pm 0.000 \mathrm{a}$ & $0.009 \pm 0.001 \mathrm{a}$ & $0.008 \pm 0.002 \mathrm{a}$ & $0.013 \pm 0.002 \mathrm{a}$ \\
\hline Succinic acid & $0.539 \pm 0.004 a$ & $1.964 \pm 0.021 b$ & $1.423 \pm 0.037 \mathrm{c}$ & $3.809 \pm 0.057 \mathrm{~d}$ & $1.041 \pm 0.003 \mathrm{e}$ & $1.162 \pm 0.026 f$ \\
\hline Tartaric acid & $0.831 \pm 0.183 a$ & $0.115 \pm 0.006 b$ & $0.218 \pm 0.002 b$ & $0.218 \pm 0.022 b$ & $0.104 \pm 0.008 b$ & $0.114 \pm 0.015 b$ \\
\hline Pyruvic acid & $\mathrm{Nd}$ & $0.124 \pm 0.010 \mathrm{a}$ & $0.248 \pm 0.004 b$ & nd & nd & nd \\
\hline
\end{tabular}

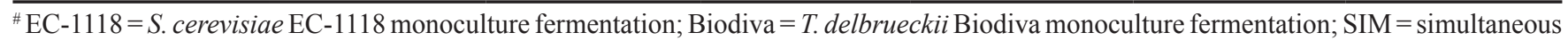
inoculation of $O$. oeni PN4 and T. delbrueckii Biodiva; SEQ $4^{\text {th }}=$ inoculation of $O$. oeni $\mathrm{PN} 4$ after four days of fermentation of $T$. delbrueckii Biodiva; SEQ $7^{\text {th }}=$ inoculation of $O$. oen $i$ PN4 after seven days of fermentation of $T$. delbrueckii Biodiva.

nd: not detected.

a,b,c,d,e,f Statistical analysis ANOVA $(n=3)$ at $95 \%$ confidence level, with same letters indicating no significant difference; the values are the means of triplicate fermentations \pm standard deviation.

than in the T. delbrueckii Biodiva control $(6.39 \%, \mathrm{v} / \mathrm{v})$, SEQ $4^{\text {th }}(6.34 \%, v / v)$ and SEQ $7^{\text {th }}(6.33 \%, v / v)$, as shown in Table 1, but no significant difference was found among all treatments. This corresponded with the results of $\mathrm{Lu}$ et al. (2017), who reported that even though the bacteria accelerated yeast death they did not affect the progress of AF.

The $\mathrm{pH}$ of all five fermentations decreased from 4.03 to around 3.95 (T. delbrueckii Biodiva control) and 3.81 (S. cerevisiae EC-1118 control) by day 2 (Fig. 1d), and then the $\mathrm{pH}$ in the two control groups increased gradually to 4.08 (T. delbrueckii Biodiva control) and 4.03 (S. cerevisiae EC1118 control) by day 14 . The decline in $\mathrm{pH}$ could be ascribed to the production of organic acids ( $\alpha$-ketoglutaric, pyruvic, succinic and lactic acids) during yeast growth (Rosi \& Canuti, 2003). In SIM, the $\mathrm{pH}$ rapidly increased to around 4.20 by day 4 and then decreased slightly to 4.17 (Fig. 1d). The $\mathrm{pH}$ in SEQ $4^{\text {th }}$ increased sharply to 4.24 by day 8 after the inoculation of $O$. oeni and then decreased gradually to 4.12 (Fig. 1d). In SEQ $7^{\text {th }}$, the $\mathrm{pH}$ gradually increased to 4.20 (day 14) after inoculation of O. oeni at day 7 (Fig. 1d). Compared with the control groups (two AFs only), larger increases in $\mathrm{pH}$ were observed in both SIM and SEQ (Fig. 1d), which agreed with previous studies (Chen \& Liu, 2016). This was likely due to the metabolism of L-malic acid by $O$. oeni in SIM and SEQ (Table 1, Fig. 2).

\section{Changes in organic acids}

The kinetics of organic acids are shown in Fig. 2. Most of the biochemical characteristics of SIM were different from SEQ $4^{\text {th }}$ and SEQ $7^{\text {th }}$ (Table 1), and the latter two SEQ were also different from each other in changes of acetic, lactic and succinic acids (Table 1, Fig. 2). It seems that the bacterial inoculation time significantly affected the concentrations of organic acids. This was consistent with several previous studies (Izquierdo et al., 2012; Nehme et al., 2010).

The largest utilisation of malic acid was found in SIM, with a residual level of $2.53 \mathrm{~g} / \mathrm{L}$, which was significantly lower than that in SEQ $4^{\text {th }}(3.53 \mathrm{~g} / \mathrm{L})$, SEQ $7^{\text {th }}(3.83 \mathrm{~g} / \mathrm{L})$ and the two control groups, with concentrations of $3.82 \mathrm{~g} / \mathrm{L}$ (EC1118 control) and $5.67 \mathrm{~g} / \mathrm{L}$ (Biodiva control) respectively (Table 1, Fig. 2).

Our results are consistent with previous studies (Chen \& Liu, 2016; Taniasuri et al., 2016), where the concentration of malic acid remained at $3.1 \mathrm{~g} / \mathrm{L}$ or $3.8 \mathrm{~g} / \mathrm{L}$ with simultaneous AF (S. cerevisiae EC-1118 or MERIT) and MLF (O. oeni Viniflora) after 28 and 20 days fermentation in durian and lychee wine respectively. As DL-malic acid was used to adjust the $\mathrm{pH}$ of durian pulp in this work, it therefore is important to note that only L-malic acid could be metabolised by $O$. oeni through decarboxylation to L-lactic acid and $\mathrm{CO}_{2}$ (Nehme et al., 2010). D-malic acid remained in the final wine, or was partially absorbed by the yeasts via passive diffusion (Chen \& Liu, 2016; Lu et al., 2016a, 2016b; Taniasuri et al., 2016). 
Ideally, enzymatic analysis of D- and L-malic acid should be carried out to ascertain their changes.

In addition, the rate of L-malic acid degradation was related to the bacterial activity, with the highest malolactic activity during day 0 to day 2 in SIM, day 5 to day 10 in SEQ $4^{\text {th }}$ and day 8 to day 14 in SEQ $7^{\text {th }}$ (Fig. 2). The influence of inoculation time of $O$. oeni on malolactic activity seems to be strain specific for each yeast-bacteria combination in wine fermentations. Our results are in line with the findings of Herrero et al. (2003), who demonstrated that the maximum malolactic activity of $O$. oen $i$ was found in its early growth stage. However, Ugliano and Moio (2005) reported that the
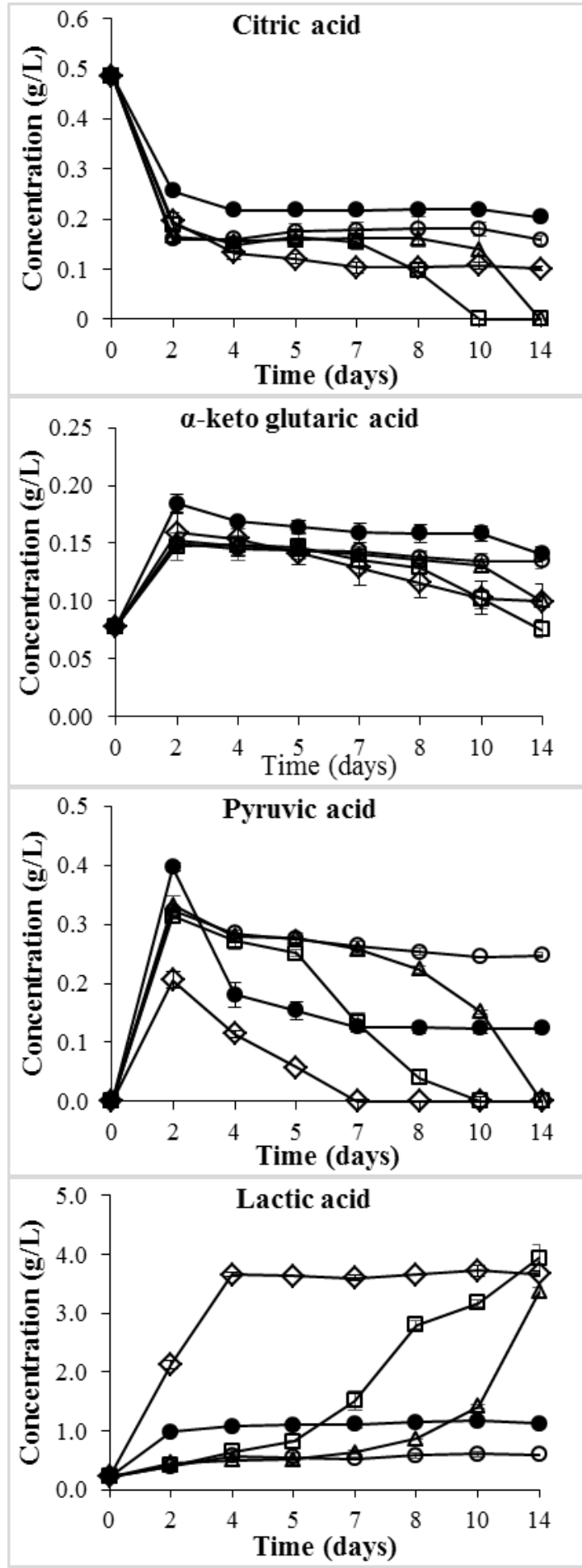
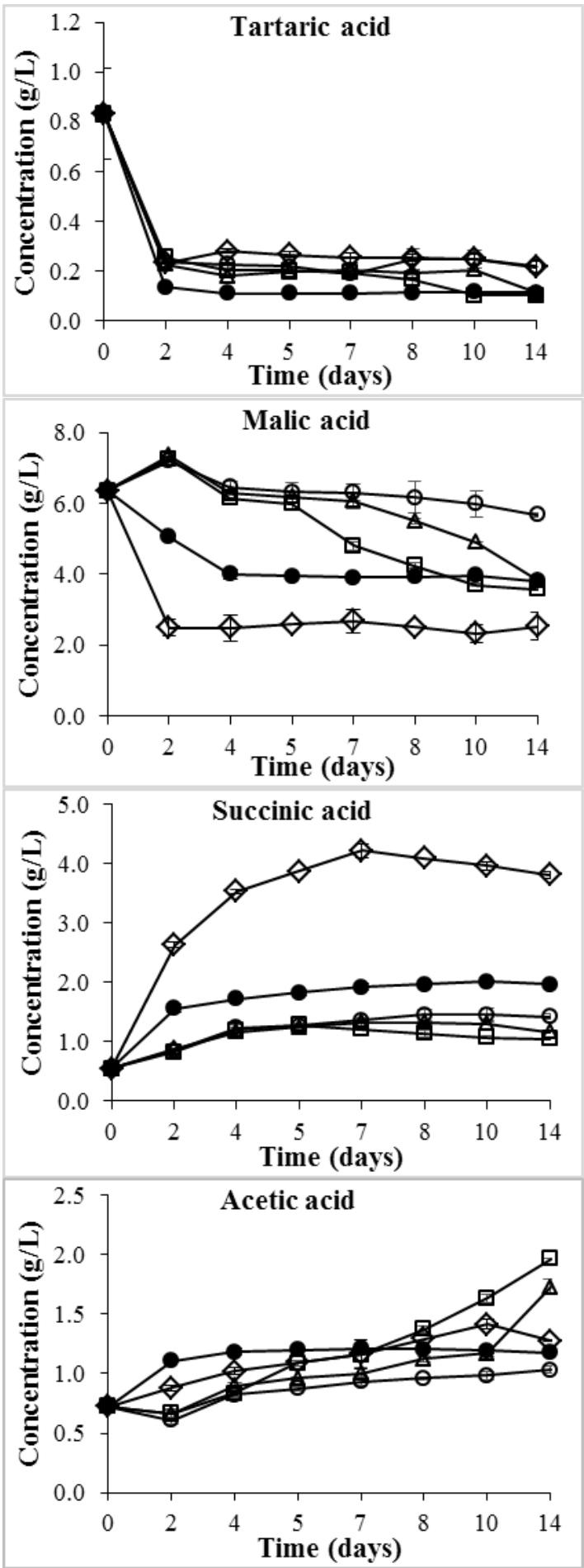

FIGURE 2

Kinetics of organic acids during durian wine fermentation. (•) S. cerevisiae EC-1118 monoculture fermentation; (०) T. delbrueckii Biodiva monoculture fermentation; $(\diamond)$ simultaneous inoculation (SIM) of T. delbrueckii Biodiva and $O$. oeni PN4; ( $\square$ ) sequential inoculation (SEQ $4^{\text {th }}$ ): O. oeni PN4 inoculated after four days of fermentation with T. delbrueckii Biodiva; $(\triangle)$ sequential inoculation (SEQ $7^{\text {th }}$ ): O. oeni PN4 inoculated after seven days of fermentation with T. delbrueckii Biodiva. The values are the means of triplicate fermentations \pm standard deviation. 


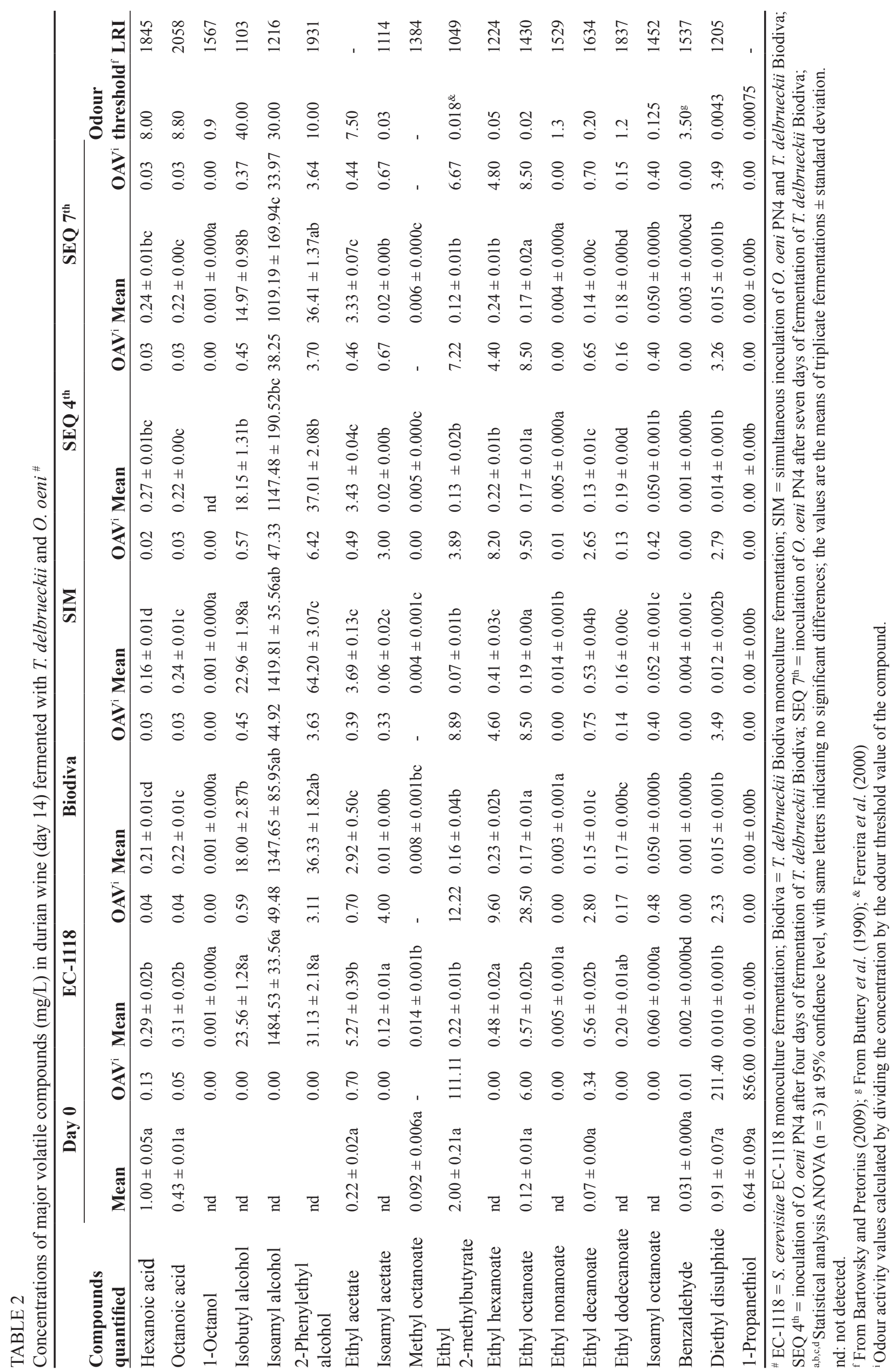


degradation of L-malic acid by $O$. oen $i$ was quite slow in the first two weeks after inoculation. This could be due to the different treatments (inducing MLF after AF completed) or different bacteria $(O$. oeni Lalvin 31, EQ 54, Lalvin O.S.U. and Uvaferm Alpha) used in different fermentations.

The production of lactic acid in SIM, SEQ $4^{\text {th }}$ and SEQ $7^{\text {th }}$ correlated with the degradation of L-malic acid (Fig. 2). The transformation of L-malic acid to L-lactic acid and $\mathrm{CO}_{2}$ is beneficial to the taste and the quality of the wine due to the reduced acidity (Ugliano \& Moio, 2005). Although the degradation of malic acid in SEQ $4^{\text {th }}$ and SEQ $7^{\text {th }}$ was less than that in SIM, comparable levels of lactic acid were produced (Table 1, Fig. 2). Maicas et al. (2002) reported that the lactic acid could be from sugars catabolised by $O$. oen $i$ via the hetero-fermentative pathway. Lactic acid could also be produced via the metabolism of citric acid by $O$. oen $i$ (Swiegers et al., 2005), which was consistent with the lower levels of citric acid in SEQ $4^{\text {th }}$ and SEQ $7^{\text {th }}$ (Table 1, Fig. 2).

Compared with the two control groups, more acetic acid was produced in SIM, SEQ $4^{\text {th }}$ and SEQ $7^{\text {th }}$ (Table 1, Fig. 2). Acetic acid could be generated from sugars via the heterofermentative pathway (Bartowsky \& Henschke, 2004), or from citric acid metabolism by $O$. oeni under the catalysis of citrate lyase (Swiegers et al., 2005; Abrahamse \& Bartowsky, 2012). This is in line with lower residual levels of citric acid (Table 1, Fig. 2). The time point of bacterial inoculation significantly affected the production of acetic acid, with the highest concentration in SEQ $4^{\text {th }}(1.97 \mathrm{~g} / \mathrm{L})$, followed by SEQ $7^{\text {th }}(1.73 \mathrm{~g} / \mathrm{L})$ and SIM $(1.28 \mathrm{~g} / \mathrm{L})$. Several studies have shown that simultaneous inoculation of malolactic bacteria with yeast could lead to relatively higher amounts of acetic acid (Abrahamse \& Bartowsky, 2012; Massera et al., 2009; Taniasuri et al., 2016), which could be ascribed to the availability of sugars in the fermented medium (Massera et al., 2009). Although the concentrations of acetic acid in all MLF treatments (SIM and SEQ) exceeded the optimum value $(0.7 \mathrm{~g} / \mathrm{L})$ in grape wines (Viana et al., 2008), it must be noted that this optimum value may not be suitable for durian wines fermented from durian pulp, which has a different composition. In addition, acetic acid is the key precursor of fruity acetate esters produced during fermentation (Swiegers et al., 2005; Chen \& Liu, 2016), and relatively higher levels of ethyl and isoamyl acetates were found in SIM and SEQ than in the T. delbrueckii Biodiva control (Table 2, Fig. 3).

The production of succinic acid varied among the different treatments (Table 1). Marked increases in succinic acid were observed in the S. cerevisiae EC-1118 and T. delbrueckii Biodiva controls, from $0.54 \mathrm{~g} / \mathrm{L}$ to $1.96 \mathrm{~g} / \mathrm{L}$ and $1.42 \mathrm{~g} / \mathrm{L}$ respectively (Table 1, Fig. 2). This agrees with previous studies, which found that $S$. cerevisiae EC-1118 (Taniasuri et al., 2016) and T. delbrueckii Biodiva (Lu et al., 2016a, 2016b) are good producers of succinic acid. A significantly higher level of succinic acid was produced in SIM (3.81 g/L) than in the two control groups (Table 1, Fig. 2). Our results are in line with the findings of Zhang and Gänzle (2010), who reported that succinic acid could be produced and contributed by Lactobacillus $s p$. via metabolising $\alpha$-ketoglutarate. This is consistent with the decrease in $\alpha$-ketoglutaric acid in SIM and SEQ (Fig. 2). Relatively lower levels of succinic acid were observed in SEQ $4^{\text {th }}(1.04 \mathrm{~g} / \mathrm{L})$ and SEQ $7^{\text {th }}(1.16 \mathrm{~g} / \mathrm{L})$ than in the T. delbrueckii Biodiva control (Table 1, Fig. 2). Taniasuri et al. (2016) reported that the decline in succinic acid in MLF could be ascribed to the transformation to fumaric acid (which could further transform to malic acid) or the corresponding ester, namely diethyl succinate. However, it must be indicated that succinic acid has an unusual bittersalty taste, and succinic acid in excess may be undesirable for the taste of the durian wine.

Pyruvic acid was produced by yeast but mainly metabolised by malolactic bacteria (Table 1, Fig. 2). The early degradation in AF only (day 2 to day 7) could be caused by the biochemical metabolism related to the production of ATP and the regeneration of $\mathrm{NAD}(\mathrm{P})^{+}$in energy conservation (Jackowetz \& Mira de Orduña, 2012). A relatively lower level of pyruvic acid $(0.12 \mathrm{~g} / \mathrm{L})$ was accumulated in the $S$. cerevisiae EC-1118 control than in the T. delbrueckii Biodiva control $(0.25 \mathrm{~g} / \mathrm{L})$, which agrees with our previous results (Lu et al., 2015). In addition, pyruvic acid could be metabolised by $S$. cerevisiae into acetaldehyde and further to ethanol (Wang et al., 2015). The pyruvic acid intermediate in SIM, SEQ $4^{\text {th }}$ and SEQ $7^{\text {th }}$ was completely consumed by $O$. oeni (Table 1, Fig. 2). This is consistent with several previous studies (Chen \& Liu, 2016; Jackowetz \& Mira de Orduña, 2012). However, Taniasuri et al. (2016) reported that similar kinetic changes and residual levels of pyruvic acid were found in AF, SIM and SEQ fermented by $S$. cerevisiae EC-1118 and $O$. oeni Viniflora. Malolactic bacteria can gain energy from the metabolism of pyruvate via the generation of acetyl-P, then ATP (Liu, 2003).

The decrease in tartaric acid in all treatments is most likely due to the precipitation of potassium bitartrate (Table 1, Fig. 2). A previous study has shown that neither yeast nor $O$. oeni could metabolise this acid during fermentation (Taniasuri et al., 2016). The small increases in oxalic acid in all fermentation could be released from durian pulp, not produced by yeast nor O. oeni (Lu et al., 2016a; Taniasuri et al., 2016).

\section{Impact of inoculation time of malolactic bacteria on volatile profiles of durian wine}

Hexanoic and octanoic acids were significantly metabolised in all fermentations, possibly to form the corresponding ethyl esters (Table 2) or to be absorbed by yeast mannoproteins released during AF or autolysis (Alexandre et al., 2004). A relatively lower level of hexanoic acid $(0.16 \mathrm{mg} / \mathrm{L})$ was detected in SIM than that in the other treatments, which is in line with the higher amount of ethyl hexanoate in SIM (Table 2, Fig. 3). Comparable levels of octanoic acid were found in all treatments, although significantly lower than that in durian pulp (Table 2). This may indicate that the different MLF inoculation regimes did not significantly affect the metabolism of octanoic acid. Our results differ from several previous studies (Pozo-Bayon et al., 2005; Taniasuri et al., 2016), in which significant increases in fatty acids (octanoic and decanoic acids) were reported after MLF. The reason might be the different yeast and bacteria used in the different fermentations. The reduction in medium-chain fatty acids in this study is desirable, as large amounts of fatty acids could inhibit the growth of both yeast and bacteria and hence could result in stuck fermentation (Alexandre et al., 2004; Viana 
et al., 2008).

Similar to ethanol, SIM produced the highest amounts of higher alcohols except for 1-octanol, while SEQ $4^{\text {th }}$ and SEQ $7^{\text {th }}$ produced comparable levels to the $T$. delbrueckii Biodiva control (Table 2, Fig. 3). Isoamyl alcohol and 2-phenylethyl alcohol increased rapidly in the first few days of fermentation and then kept stable or gradually reduced (Fig. 3). The increases in these higher alcohols could contribute to the
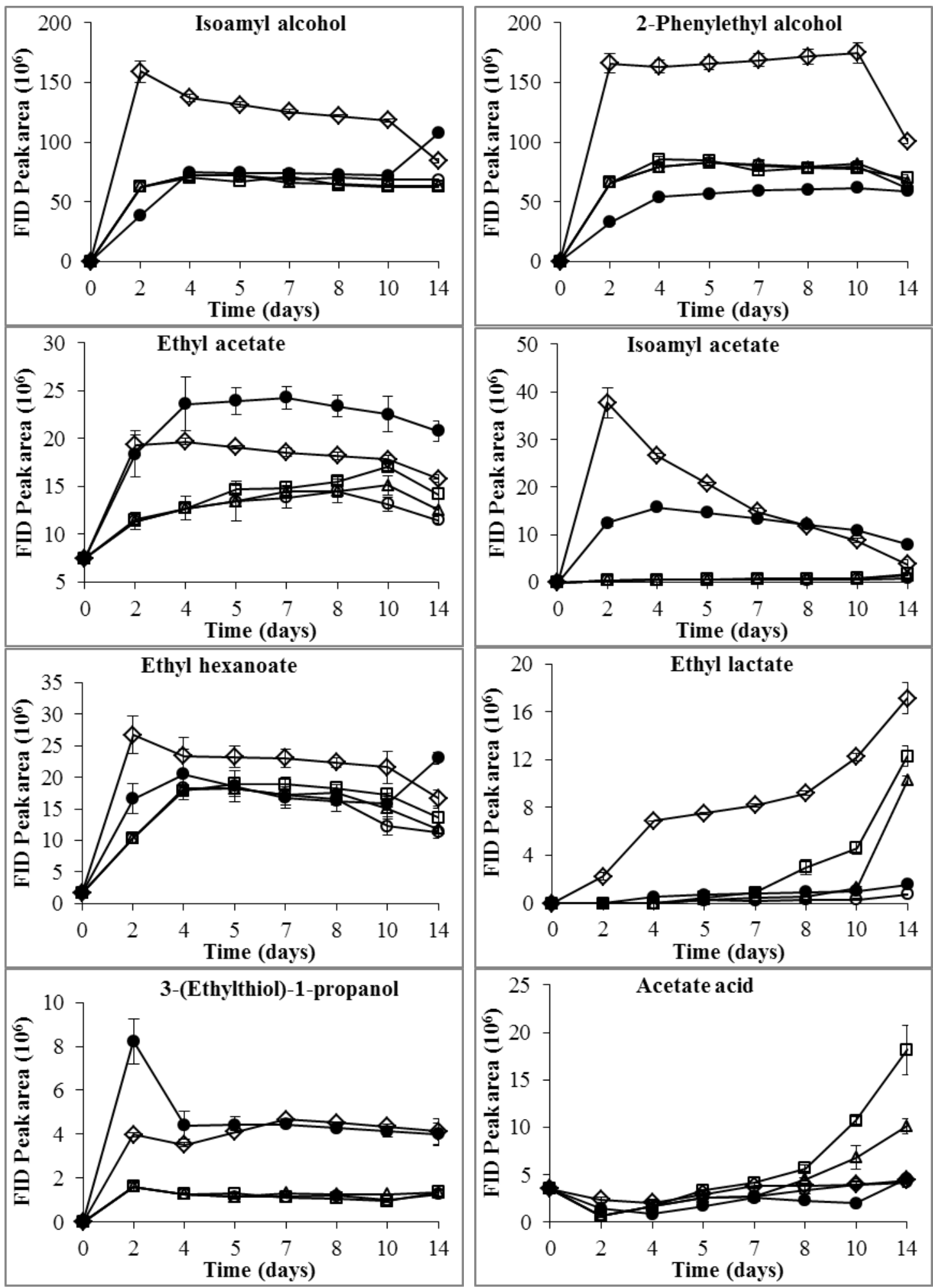

FIGURE 3

Kinetics of ethanol, acetic acid, isoamyl acetate, ethyl acetate, ethyl hexanoate and ethyl lactate during durian wine fermentation. (•) S. cerevisiae EC-1118 monoculture fermentation; ( ( ) T. delbrueckii Biodiva monoculture fermentation; $(\diamond)$ simultaneous inoculation (SIM) of $T$. delbrueckii Biodiva and O. oeni PN4; ( $\square$ ) sequential inoculation (SEQ $\left.4^{\text {th }}\right)$ : O. oeni PN4 inoculated after four days of fermentation with $T$. delbrueckii Biodiva; $(\Delta)$ sequential inoculation (SEQ $7^{\text {th }}$ ): $O$. oeni PN4 inoculated after seven days of fermentation with $T$. delbrueckii Biodiva. The values are the means of triplicate fermentations \pm standard deviation. 


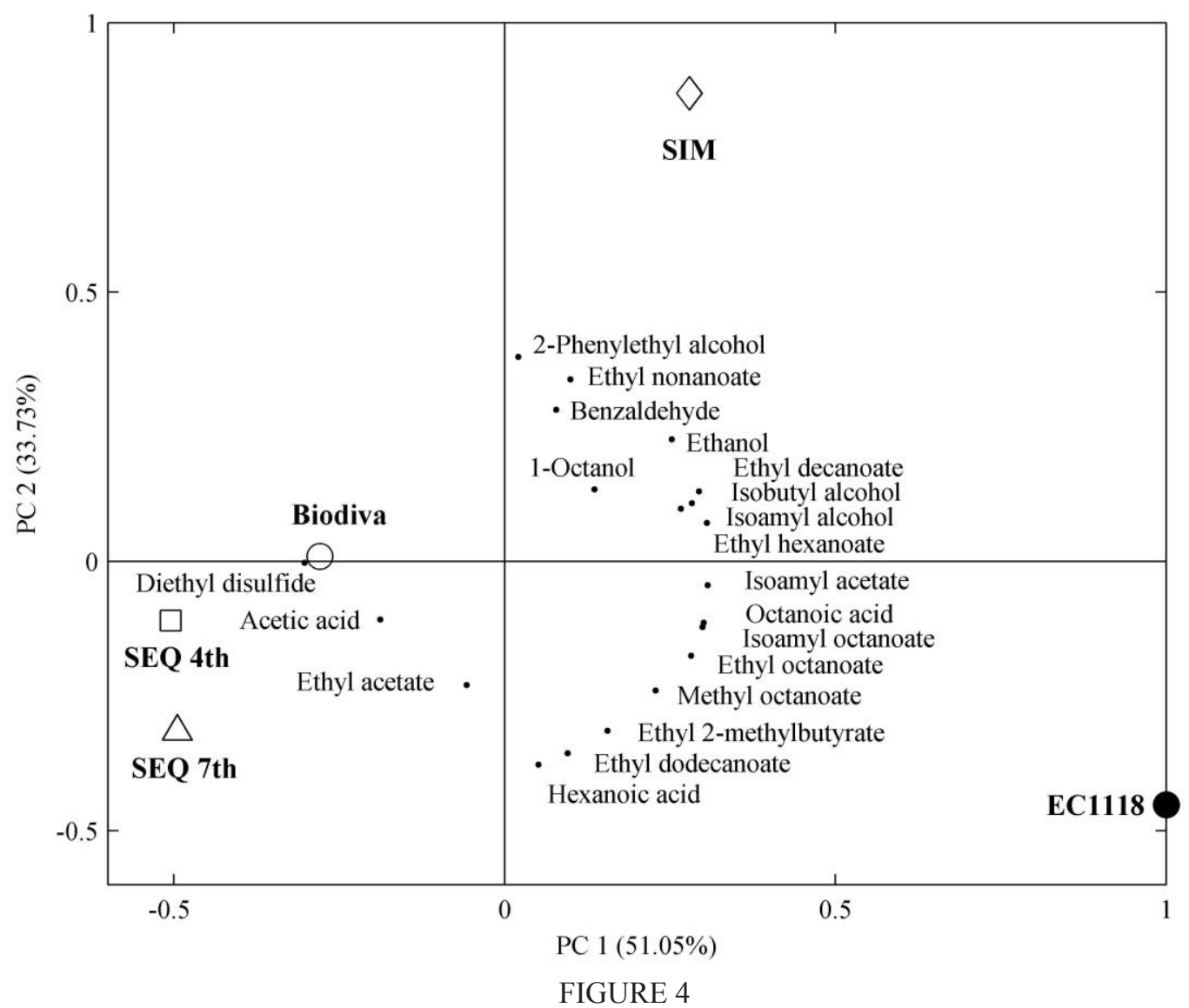

Bi-plot of principal component analysis of durian wine fermented with S. cerevisiae EC-1118, T. delbrueckii Biodiva and O. oeni PN4. SIM: Simultaneous inoculation of T. delbrueckii Biodiva and O. oeni PN4; SEQ $4^{\text {th }}$ O. oeni PN4 sequentially inoculated after four days of fermentation with $T$. delbrueckii Biodiva; SEQ $7^{\text {th }}$ : O. oeni PN4 sequentially inoculated after seven days of fermentation with $T$. delbrueckii Biodiva.

fruity notes and aroma complexity of durian wines. De Revel et al. (1999) observed the increase in isoamyl alcohol after simultaneous MLF, while Jeromel et al. (2008) found increases in isobutyl alcohol and 2-phenylethyl alcohol after simultaneous MLF. In contrast, several studies have shown that similar levels of higher alcohols are observed in simultaneous MLF as compared to AF only (Abrahamse \& Bartowsky, 2012; Chen \& Liu, 2016; Taniasuri et al., 2016). This discrepancy could be due to the different yeasts used (S. cerevisiae and $O$. oeni). The reduction in these higher alcohols at the later stage of fermentation could be ascribed to the production of corresponding esters (Table 2). The concentrations of isoamyl alcohol $(30 \mathrm{mg} / \mathrm{L}$, in $10 \%$ ethanol $\mathrm{v} / \mathrm{v})$ and 2-phenylethyl alcohol $(10 \mathrm{mg} / \mathrm{L}$, in $10 \%$ ethanol $\mathrm{v} / \mathrm{v})$ were higher than their odour thresholds and could impart alcoholic and whiskey, floral and rose aroma notes to the final wines (Table 2).

Most esters that are endogenously present in durian pulp, such as methyl 2-methylbutyrate and ethyl 2-methylbutyrate, were catabolised during fermentation (Table 2). Various esters, such as ethyl esters (ethyl esters of hexanoate, octanoate, nonanoate, decanoate and dodecanoate) and acetate esters (ethyl acetate and isoamyl acetate), were produced by yeast during AF (Table 2). The production of these esters would compensate for the loss of the endogenous fruity esters. The final levels of esters in MLF wines seemed to be related to the inoculation time of O. oeni. SIM produced relatively higher levels of ethyl esters than those in SEQ $4^{\text {th }}$, SEQ $7^{\text {th }}$ and the $T$. delbrueckii Biodiva control (Table 2). Ethyl esters of hexanoate, octanoate and decanoate are associated with fruity notes with concentrations well above their odour detection thresholds (Table 2). This would contribute fruity sensory properties to durian wines (Francis \& Newton, 2005).

Ethyl lactate is quantitatively the most important ester produced during MLF (Pozo-Bayon et al., 2005). SIM produced the highest amount of ethyl lactate, followed by SEQ $4^{\text {th }}$ and SEQ $7^{\text {th }}$ (Fig. 3). The ethyl lactate in SIM, SEQ $4^{\text {th }}$ and SEQ $7^{\text {th }}$ were approximately 22, 16 and 13 times higher than that produced by the $T$. delbrueckii Biodiva control respectively (Fig. 3). All MLF treatments also produced more ethyl lactate than the $S$. cerevisiae EC-1118 control (Fig. 3). The production of ethyl lactate was significantly associated with its precursor (lactic acid) produced during MLF (Fig. 2, Table 2), and this was consistent with previous studies (Abrahamse \& Bartowsky, 2012; Chen \& Liu, 2016). Other than imparting fruity notes to durian wines, ethyl lactate could also increase mouthfeel (Ugliano \& Moio, 2005), while its odour detection threshold (around $14 \mathrm{mg} / \mathrm{L}$ ) was relatively higher than that of the other ethyl esters (Francis \& Newton, 2005).

Acetate esters are formed from the corresponding higher 
alcohols and acetyl-CoA(Swiegers et al., 2005). The amounts of ethyl acetate and isoamyl acetate in SIM were higher than that in the T. delbrueckii Biodiva control and SEQ, but less than in the $S$. cerevisiae EC-1118 control (Table 2, Fig. 3). Ethyl acetate in all treatments was lower than its odour detection threshold $(7.50 \mathrm{mg} / \mathrm{L}$, in $10 \%$ ethanol $\mathrm{v} / \mathrm{v})$ and may not significantly influence the sensory properties of the wine, while isoamyl acetate in SIM was higher than its odour detection threshold $(0.03 \mathrm{mg} / \mathrm{L}$, in $10 \%$ ethanol $\mathrm{v} / \mathrm{v})$. The concentrations of acetate esters in SIM increased rapidly by day 2 and then remained stable or declined gradually (Fig. 3). Acetate esters are also associated with fruity aroma, and isoamyl acetate could contribute a banana-like note. Our results agree with several previous findings (Abrahamse \& Bartowsky, 2012; Massera et al., 2009; Taniasuri et al., 2016), in which SIM wines scored higher in fruity feature than SEQ wines.

Diacetyl is normally formed after MLF, but it was not found in durian pulp or in durian wines. It might have been reduced to acetoin or 2,3-butanediol (Chen \& Liu, 2016; Knoll et al., 2011). Regardless of the inoculation regimes, aldehydes that were initially present in durian pulp, including acetaldehyde, hexanal and nonanal, were catabolised to undetectable levels in all treatments (data not shown). These aldehydes might be reduced to the respective alcohols or oxidised to acids, and even be used to form esters (Sumby et al., 2010). Benzaldehyde was metabolised to low levels in all treatments (Table 2), and may be transformed to benzylalcohol (Delfini et al., 2015), L-phenylacetyl carbinol (Agarwal et al., 1987) or benzoic acid by yeast employing benzaldehyde as the precursor. MLF wines contained relatively higher residual levels of benzaldehyde (Table 2), which could be ascribed to the metabolism of L-phenylalanine by LAB, such as $O$. oeni.

Volatile sulphur compounds (VSCs) are significant compounds in durian pulp and can also contribute to the wine aroma. Previous studies showed that some VSCs could even determine wine quality, with a positive bouquet aroma contribution based on their concentrations (Landaud et al., 2008). Most of the endogenous VSCs in durian pulp were catabolised to undetectable (e.g. ethanethiol, 1-propanethiol) or trace levels (diethyl disulphide) (Table 2). This agrees with previous studies (Lee et al., 2012; Lu etal., 2016a, 2016b). The reactive thiols, such as ethanethiol and 1-propanethiol, might be oxidised to their respective disulphides by trace levels of metal ions in the fermented medium, or form non-volatile thiols by reacting with polymeric phenols (Nikolantonaki et al., 2010). In addition, thiols could also be consumed by cell wall mannoproteins of yeast lees by forming disulphide bridges (Nikolantonaki et al., 2010). Furthermore, sulphides could be reduced to the corresponding thiols by yeast under anaerobic conditions (Gómez-Plaza \& Cano-López, 2011), and the thiols that form could be degraded further, as mentioned above.

The production of new VSCs such as 3-(ethylthio)1-propanol (Fig. 3) could make up for the weak onionlike odour caused by the loss of initial VSCs. SIM wines produced comparable levels of 3-(ethylthio)-1-propanol to the $S$. cerevisiae EC-1118 control, which were significantly higher than that in the T. delbrueckii Biodiva control and
SEQ (Fig. 3). The presence of 3-(ethylthio)-1-propanol has been noted in grape wines (Moreira et al., 2011), which might be from the metabolism of methionine (Noguerol-Pato et al., 2011). The production of 3-(ethylthio)-1-propanol could be affected by the nitrogen content of the fermented medium (Moreira et al., 2011). Amino acids are the most important nitrogen source for LAB metabolism during wine fermentation, and $O$. oeni could convert methionine into various VSCs, such as methional and 2-oxo-4-(methylthio)butyric acid (Vallet et al., 2008). However, Izquierdo et al. (2014) reported that $O$. oeni only played a minor role in the production of VSCs during MLF. Above all, the metabolic pathway for the formation of 3-(ethylthio)-1-propanol in $O$. oeni has not yet been elucidated.

\section{Multivariate data analysis of durian wine}

Acetic acid and ethanol from Table 1 and all volatile compounds from Table 2 were analysed by applying principal component analysis (PCA) to distinguish the particular characteristics of durian wines produced by different treatments. The first two principle components (PCs) accounted for $84.78 \%$ of the total variation, with $\mathrm{PC} 1$ and PC2 accounting for $51.05 \%$ and $33.73 \%$ respectively (Fig. 4). Wines were separated on the basis of their different aroma compositions, with the $S$. cerevisiae EC-1118 control and SIM on the right half of the plot, while the T. delbrueckii Biodiva control, SEQ $4^{\text {th }}$ and SEQ $7^{\text {th }}$ are located on the left half (Fig. 4). PC2 separates SIM from other treatments due to its relatively higher levels of higher alcohols (2-phenylethyl alcohol, isoamyl alcohol, isobutyl alcohol and 1-octanol), ethyl hexanoate, ethyl nonanoate and ethyl decanoate (Fig. 4). SEQ $4^{\text {th }}$ and SEQ $7^{\text {th }}$, positioned in the negative part of PC1 with the T. delbrueckii Biodiva control, indicate their similar volatile compositions, which are higher in acetic acid, diethyl disulphide and ethyl acetate.

\section{CONCLUSIONS}

This work reported for the first time the impact of MLF inoculation regimes on the fermentation kinetics and chemical components of durian wines fermented with T. delbrueckii Biodiva and O. oeni PN4. The inoculation time of $O$. oeni significantly adversely affected the population persistence of $T$. delbrueckii, especially in SIM and SEQ $4^{\text {th }}$. However, the metabolism of yeasts in the early stage of AF may stimulate the growth of the malolactic bacteria in SEQ $4^{\text {th }}$ and SEQ $7^{\text {th }}$. The final concentrations of organic acids and the production of esters in MLF wines varied with the timing of inoculation. SIM produced the highest amount of ethanol (6.93\%), with sugars almost depleted. In addition, the relatively higher levels of ethyl esters, acetate esters and succinic acid produced in SIM could contribute fruity properties and modify mouthfeel. Therefore, SIM treatment would be an effective tool to produce durian wines with more fruity notes while retaining unique durian odour.

\section{LITERATURE CITED}

Abrahamse, C.E. \& Bartowsky, E.J., 2012. Timing of malolactic fermentation inoculation in Shiraz grape must and wine: Influence on chemical composition. World J. Microbiol. Biotechnol. 28, 255-265. 
Agarwal, S., Basu, S., Vora, V., Mason, J. \& Pirt, S., 1987. Studies on the production of L-acetyl phenyl carbinol by yeast employing benzaldehyde as precursor. Biotechnol. Bioeng. 29, 783-785.

Alexandre, H., Costello, P.J., Remize, F., Guzzo, J. \& Guilloux-Benatier, M., 2004. Saccharomyces cerevisiae-Oenococcus oeni interactions in wine: current knowledge and perspectives. Int. J. Food Microbiol. 93, 141-154.

Bartowsky, E.J. \& Henschke, P.A., 2004. The buttery attribute of winediacetyl-desirability, spoilage and beyond. Int. J. Food Microbiol. 96, 235252 .

Bartowsky, E.J. \& Pretorius, I.S., 2009. Microbial formation and modification of flavor and off-flavor compounds in wine. Biology of Microorganisms on Grapes, in Must and in Wine, 209-232.

Bely, M., Stoeckle, P., Masneuf-Pomarède, I. \& Dubourdieu, D. 2008. Impact of mixed Torulaspora delbrueckii-Saccharomyces cerevisiae culture on high-sugar fermentation. Int. J. Food Microbiol. 122(3), 312-320.

Buttery, R.G., Teranishi, R., Ling, L.C. \& Turnbaugh, J.G., 1990 Quantitative and sensory studies on tomato paste volatiles. J Agric. Food Chem., 38, 336-340.

Byarugaba-Bazirake, G.W., Van Rensburg, P. \& Kyamuhangire, W., 2013. The influence of commercial enzymes on wine clarification and on the sensory characteristics of wines made from three banana cultivars. Am. J. Biotechnol. Mol. Sci. 3, 41-62.

Chen, D. \& Liu, S.Q., 2016. Transformation of chemical constituents of lychee wine by simultaneous alcoholic and malolactic fermentations. Food Chem. 196, 988-995.

Delfini, C., Gaia, P., Bardi, L., Mariscalco, G., Contiero, M. \& Pagliara, A., 2015. Production of benzaldehyde, benzyl alcohol and benzoic acid by yeasts and Botrytis cinerea isolated from grape musts and wines. Vitis-J. Grapevine Res. 30, 253.

De Revel, G., Martin, N., Pripis-Nicolau, L., Lonvaud-Funel, A. \& Bertrand, A., 1999. Contribution to the knowledge of malolactic fermentation influence on wine aroma. J. Agric. Food Chem. 47, 4003-4008.

Ferreira, V., Lopez, R. \& Cacho, J.F., 2000. Quantitative determination of the odorants of young red wines from different grape varieties. J. Sci. Food Agric. 80, 1659-1667.

Francis, I. \& Newton, J., 2005. Determining wine aroma from compositional data. Aust. J. Grape Wine Res. 11, 114-126.

Garofalo, C., El Khoury, M., Lucas, P., Bely, M., Russo, P., Spano, G. \& Capozzi, V., 2015. Autochthonous starter cultures and indigenous grape variety for regional wine production. J. Appl. Microbiol. 118(6), 1395-1408.

Gómez-Plaza, E. \& Cano-López, M., 2011. A review on micro-oxygenation of red wines: Claims, benefits and the underlying chemistry. Food Chem. $125,1131-1140$

Graves, T., Narendranath, N.V., Dawson, K. \& Power, R., 2007. Interaction effects of lactic acid and acetic acid at different temperatures on ethanol production by Saccharomyces cerevisiae in corn mash. Appl. Microbiol. Biotechnol. 73, 1190-1196.

Guth, H., 1997. Quantitation and sensory studies of character impact odorants of different white wine varieties. J. Agric. Food Chem. 45, 30273032 .

Haruenkit, R., Poovarodom, S., Vearasilp, S., Namiesnik, J., SliwkaKaszynska, M., Park, Y.S., Heo, B.G., Cho, J.Y., Jang, H.G. \& Gorinstein, S., 2010. Comparison of bioactive compounds, antioxidant and antiproliferative activities of Mon Thong durian during ripening. Food Chem. 118, 540-547.

Herrero, M., García, L.A. \& Díaz, M., 2003. Malolactic bioconversion using a Oenococcus oeni strain for cider production: effect of yeast extract supplementation. J. Ind. Microbiol. Biotechnol. 30, 699-704.
Ho, L.H. \& Bhat, R., 2015. Exploring the potential nutraceutical values of durian (Durio zibethinus L.) - An exotic tropical fruit. Food Chem. 168, 80-89.

Izquierdo, P.M., García-Romero, E., Manso, J.M.H. \& Fernández-González, M., 2014. Influence of sequential inoculation of Wickerhamomyces anomalus and Saccharomyces cerevisiae in the quality of red wines. Eur. Food Res. Technol. 239, 279-286.

Izquierdo, P.M., Pérez-Martín, F., Romero, E.G., Prieto, S.S. \& Herreros, M.d.1.L.P., 2012. Influence of inoculation time of an autochthonous selected malolactic bacterium on volatile and sensory profile of Tempranillo and Merlot wines. Int. J. Food Microbiol. 156, 245-254.

Jackowetz, J. \& Mira de Orduña, R., 2012. Metabolism of $\mathrm{SO}_{2}$ binding compounds by Oenococcus oeni during and after malolactic fermentation in white wine. Int. J. Food Microbiol. 155, 153-157.

Jeromel, A., Herjavec, S., Orlić, S., Redžepović, S. \& Wondra, M., 2008. Changes in volatile composition of Kraljevina wines by controlled malolactic fermentation. J. Central Euro. Agric. 9, 363-372.

Jussier, D., Morneau, A.D. \& Mira de Orduña, R., 2006. Effect of simultaneous inoculation with yeast and bacteria on fermentation kinetics and key wine parameters of cool-climate Chardonnay. Appl. Environ. Microbiol. 72, 221-227.

Knoll, C., Fritsch, S., Schnell, S., Grossmann, M., Rauhut, D. \& Du Toit, M., 2011. Influence of $\mathrm{pH}$ and ethanol on malolactic fermentation and volatile aroma compound composition in white wines. LWT - Food Sci. Technol. 44, 2077-2086.

Landaud, S., Helinck, S. \& Bonnarme, P., 2008. Formation of volatile sulfur compounds and metabolism of methionine and other sulfur compounds in fermented food. Appl. Microbiol. Biotechnol. 77, 1191-1205.

Lee, P.R., Ong, Y.L., Yu, B., Curran, P. \& Liu, S.Q., 2010. Evolution of volatile compounds in papaya wine fermented with three Williopsis saturnus yeasts. Int. J. Food Sci. Technol. 45, 2032-2041.

Lee, P.R., Saputra, A., Yu, B., Curran, P. \& Liu, S.Q., 2012. Biotransformation of durian pulp by mono- and mixed-cultures of Saccharomyces cerevisiae and Williopsis saturnus. LWT - Food Sci. Technol. 46, 84-90.

Liu, S.Q., 2003. Practical implications of lactate and pyruvate metabolism by lactic acid bacteria in food and beverage fermentations. Int. J. Food Microbiol. 83(2), 115-131

Lu, Y., Chua, J.Y., Huang, D., Lee, P.R. \& Liu, S.Q., 2016b. Biotransformation of chemical constituents of durian wine with simultaneous alcoholic fermentation by Torulaspora delbrueckii and malolactic fermentation by Oenococcus oeni. Appl. Microbiol. Biotechnol. 100, 8877-8888.

Lu, Y., Chua, J.Y., Huang, D., Lee, P.R. \& Liu, S.Q., 2017. Chemical consequences of three commercial strains of Oenococcus oeni co-inoculated with Torulaspora delbrueckii in durian wine fermentation. Food Chem. 215, 209-218.

Lu, Y., Huang, D., Lee, P.R. \& Liu, S.Q., 2015. Effects of cofermentation and sequential inoculation of Saccharomyces bayanus and Torulaspora delbruckii on durian wine composition. Int. J. Food Sci. Technol. 50, 26532663.

Lu, Y., Huang, D., Lee, P.R. \& Liu, S.Q., 2016a. Assessment of volatile and non-volatile compounds in durian wines fermented with four commercial non-Saccharomyces yeasts. J. Sci. Food Agric. 96, 1511-1521.

Maicas, S., Ferrer, S. \& Pardo, I., 2002. NAD (P) H regeneration is the key for heterolactic fermentation of hexoses in Oenococcus oeni. Microbiol. $148,325-332$.

Massera, A., Soria, A., Catania, C., Krieger, S. \& Combina, M., 2009. Simultaneous inoculation of Malbec (Vitis vinifera) musts with yeast and bacteria: Effects on fermentation performance, sensory and sanitary attributes of wines. Food Technol. Biotechnol. 47, 192-201. 
Mendoza, L.M., Merín, M.G., Morata, V.I. \& Farías, M.E., 2011. Characterization of wines produced by mixed culture of autochthonous yeasts and Oenococcus oeni from the northwest region of Argentina. J. Ind. Microbiol. Biotechnol. 38, 1777-1785.

Moreira, N., De Pinho, P.G., Santos, C. \& Vasconcelos, I., 2011. Relationship between nitrogen content in grapes and volatiles, namely heavy sulfur compounds, in wines. Food Chem. 126, 1599-1607.

Nehme, N., Mathieu, F. \& Taillandier, P., 2010. Impact of the co-culture of Saccharomyces cerevisiae-Oenococcus oeni on malolactic fermentation and partial characterization of a yeast-derived inhibitory peptidic fraction. Food Microbiol. 27, 150-157.

Nikolantonaki, M., Chichuc, I., Teissedre, P.L. \& Darriet, P., 2010. Reactivity of volatile thiols with polyphenols in a wine-model medium: Impact of oxygen, iron, and sulfur dioxide. Anal. Chim. Acta. 660, 102-109.

Noguerol-Pato, R., González-Rodríguez, R., González-Barreiro, C., Cancho-Grande, B. \& Simal-Gándara, J., 2011. Influence of tebuconazole residues on the aroma composition of Mencía red wines. Food Chem. 124, 1525-1532.

Pozo-Bayon, M.A., Alegria, G.E., Polo, M.C., Tenorio, C., Martin-Alvarez, P.J., De la Banda, M.T.C., Ruiz-Larrea, F. \& Moreno-Arribas, M.V., 2005. Wine volatile and amino acid composition after malolactic fermentation: effect of Oenococcus oeni and Lactobacillus plantarum starter cultures. J. Agric. Food Chem. 53, 8729-8735.

Rosi, I. \& Canuti, V., 2003. Influence of different $\mathrm{pH}$ values and inoculation time on the growth and malolactic activity of a strain of Oenococcus oeni. Aust. J. Grape Wine Res. 9, 194-199.

Sumby, K.M., Grbin, P.R. \& Jiranek, V., 2010. Microbial modulation of aromatic esters in wine: Current knowledge and future prospects. Food Chem. 121, 1-16

Sun, S.Y., Che, C.Y., Sun, T.F., Lv, Z.Z., He, S.X., Gu, H.N., Shen, W.J., Chi, D.C. \& Gao, Y., 2013. Evaluation of sequential inoculation of Saccharomyces cerevisiae and Oenococcus oeni strains on the chemical and aromatic profiles of cherry wines. Food Chem. 138, 2233-2241.
Swiegers, J.H., Bartowsky, E.J., Henschke, P.A. \& Pretorius, I.S., 2005. Yeast and bacterial modulation of wine aroma and flavour. Aust. J. Grape Wine Res. 11, 139-173.

Taniasuri, F., Lee, P.R. \& Liu, S.Q., 2016. Induction of simultaneous and sequential malolactic fermentation in durian wine. Int. J. Food Microbiol. 230, 1-9.

Tristezza, M., Tufariello, M., Capozzi, V., Spano, G., Mita, G. \& Grieco, F. (2016). The oenological potential of Hanseniaspora uvarum in simultaneous and sequential co-fermentation with Saccharomyces cerevisiae for industrial wine production. Front. Microbiol. 7, 1-14.

Tristezza, M., Vetrano, C., Bleve, G., Spano, G., Capozzi, V., Logrieco, A., Mita, G. \& Grieco, F. (2013). Biodiversity and safety aspects of yeast strains characterized from vineyards and spontaneous fermentations in the Apulia Region, Italy. Food Microbiol. 36(2), 335-342.

Ugliano, M. \& Moio, L., 2005. Changes in the concentration of yeastderived volatile compounds of red wine during malolactic fermentation with four commercial starter cultures of Oenococcus oeni. J. Agric. Food Chem. 53, 10134-10139.

Vallet, A., Lucas, P., Lonvaud-Funel, A. \& De Revel, G., 2008. Pathways that produce volatile sulfur compounds from methionine in Oenococcus oeni. J. Appl. Microbiol. 104, 1833-1840.

Viana, F., Gil, J.V., Genovés, S., Vallés, S. \& Manzanares, P., 2008. Rational selection of non-Saccharomyces wine yeasts for mixed starters based on ester formation and enological traits. Food Microbiol. 25, 778-785.

Wang, D., Wang, L., Hou, L., Deng, X., Gao, Q. \& Gao, N., 2015. Metabolic engineering of Saccharomyces cerevisiae for accumulating pyruvic acid. Ann. Microbiol. 65, 2323-2331.

Zhang, C. \& Gänzle, M., 2010. Metabolic pathway of $\alpha$-ketoglutarate in Lactobacillus sanfranciscensis and Lactobacillus reuteri during sourdough fermentation. J. Appl. Microbiol. 109, 1301-1310. 